\title{
Open Government Data Licences in the Greater China Region
}

\author{
Jyh-An Lee
}

\section{Introduction}

Governments around the world create and collect an enormous amount of data that covers important environmental, educational, geographical, meteorological, scientific, demographic, transport, tourism, health insurance, crime, occupational safety, product safety and many other types of information. ${ }^{2}$ This data is generated as part of a government's daily functions. ${ }^{3}$ Given the exceptional social and economic value of some government data, former United States President Barack Obama

1 Copyright (C) 2018 Jyh-An Lee. Associate Professor at the Faculty of Law in the Chinese University of Hong Kong. The author is grateful to Susan Corbett and Jessica Lai for their helpful comments. This study was supported by a grant from the Research Grants Council in Hong Kong (Project No. CUHK 14612417).

2 Keiran Hardy and Alana Maurushat 'Opening Up Government Data for Big Data Analysis and Public Benefit' (2017) 33 CLSR 30 at 31; National Archives UK Government Licensing Framework for public sector information (5th ed, January 2016) [UK Licensing Framework]; Joshua Tauberer The Principles and Practices of Open Government Data (2nd ed, self-published, 2014); Katleen Janssen 'The Influence of the PSI Directive on Open Government Data: An Overview of Recent Developments' (2011) 28 Government Information Quarterly 446 at 446; Barbara Ubaldi Open Government Data: Towards Empirical Analysis of Open Data Initiatives (Organisation for Economic Cooperation and Development, Working Papers on Public Governance 22, 2013) at 4.

3 Miriam Marcowitz-Bitton 'Commercializing Public Sector Information' (2015) 97 JPTOS 412 at 413 . 
described it as a 'national asset'. ${ }^{4}$ For various policy reasons, in recent years, open government data (OGD) has become a popular governmental practice and an international movement associated with free access to government data by everyone. ' 'Open government' has therefore acquired a new meaning empowered by digital technologies and data science. ${ }^{6}$ It is estimated that more than 250 national or local governments from around 50 developed and developing countries have launched OGD initiatives. ${ }^{7}$ Data.gov, established by the United States Federal Government, and Data. gov.uk, launched by the British Government, are both notable examples of data portals through which governments make their data available to the public. ${ }^{8}$ In the Greater China region, Taiwan led the wave by promoting OGD as a national policy in 2012. China's Premier Le Keqiang made a public statement in 2015 supporting OGD, whereas Hong Kong built its first OGD portal in 2016. These developments are discussed in more detail later in the chapter.

In July 2013, G8 leaders signed the G8 Open Data Charter, which outlined five fundamental open data principles. ${ }^{9}$ Two years earlier, the international OGD movement led to the establishment of the Open

4 The White House Office of the Press Secretary 'Obama Administration Releases Historic Open Data Rules to Enhance Government Efficiency and Fuel Economic Growth' (press release, 9 May 2013).

5 See Joel Gurin Open Data Now: The Secret to Hot Startups, Smart Investing, Savvy Marketing, and Fast Innovation (McGraw-Hill, New York, 2014) at 216-218; Anneke Zuiderwijk and Marijn Janssen 'Open Data Policies, Their Implementation and Impact: A Framework for Comparison' (2014) 31 Government International Quarterly 17 at 17; Teresa Scassa 'Public Transit Data Through an Intellectual Property Lens: Lessons About Open Data' (2014) 41 Fordham Urb LJ 1759 at 1760; Deirdre Lee, Richard Cyganiak and Stefan Decker Open Data Ireland: Best Practice Handbook (Department of Public Expenditure and Reform, Government of Ireland, May 2014) at 26.

6 See Jillian Raines 'The Digital Accountability and the Transparency Act of 2011 (DATA): Using Open Data Principles to Revamp Spending Transparency Legislation' (2013) NYL Sch L Rev 313 at 321-324; Nataša Veljković, Sanja Bogdanović-Dinić and Leonid Stoimenov 'Benchmarking Open Government: An Open Data Perspective' (2014) 31 Government Information Quarterly 278 at 278 279; Jeremy Weinstein and Joshua Goldstein 'The Benefits of A Big Tent: Opening Up Government in Developing Countries: A Response to Yu \& Robinson's The New Ambiguity of “Open Government" (2012) 60 UCLA Law Rev Disc 38 at 40-41 (noting the distinction between and the convergence of the 'technologies for open data' and 'politics of open government') citing Harlan Yu and David G Robinson 'The New Ambiguity of Open Government' (2012) 59 UCLA Law Rev Disc 178 at 205.

7 'Open Data in 60 Seconds' The World Bank opendatatoolkit.worldbank.org.

8 Data.gov www.data.gov; Data.gov.uk data.gov.uk; see Gurin, above n 5, at 10-11 and 218; Yu and Robinson, above n 6, at 198 and 200; Jean-Louis Monino and Soraya Sedkaoui Big Data, Open Data and Data Development (Wiley-ISTE, New Jersey, 2016) vol 3 at xxxv (noting that these are the two leading nations globally in promoting open data policies); Esteve Sanz 'Open Governments and Their Cultural Transitions' in Mila Gascó-Hernández (ed) Open Government: Opportunities and Challenges for Public Governance (Springer, New York, 2014) 1 at 11 (describing the role of Data.gov).

9 Open Data Charter (Cabinet Office (UK), Policy Paper, 18 June 2013) at 8. 
Government Partnership (OGP), 'a multilateral initiative that aims to secure concrete commitments from governments to promote transparency, empower citizens, fight corruption, and harness new technologies to strengthen governance'. ${ }^{10}$ The OGP was initiated by eight national governments (Brazil, Indonesia, Mexico, Norway, the Philippines, South Africa, the United Kingdom and the United States) ${ }^{11}$ with the proclamation of the Open Government Declaration on 20 September 2011. ${ }^{12}$ Sixty-seven additional national governments have joined the OGP since its incorporation. ${ }^{13}$ In total, 75 governments altogether have made more than 2,500 commitments to implement open data policies. ${ }^{14}$ International organisations, such as the World Bank, have also actively advocated for and implemented open data policies. ${ }^{15}$

Businesses are also embracing the OGD trend as reflected in new strategies, applications, products and services. For example, Microsoft introduced the 'Open Government Data Initiative' to promote the company's Window Azure online platform as a tool for OGD. ${ }^{16}$ Government data has become an increasingly important strategic source for entrepreneurship, innovation and economic growth. ${ }^{17}$ Businesses may aggregate, repack and redistribute the data, develop new applications and platforms, combine the data with other information or explore novel ways to add value to government data. Enterprises can make use of such data to provide services relating to travel, business planning, medical decisions and so on. ${ }^{18}$ The commercial value of this volume of government data is increasingly apparent in the 'Big Data' technology environment, where enormous amounts of datasets are analysed digitally to discover patterns

10 'About OGP: What is the Open Government Partnership?' Open Government Partnership [OGP] www.opengovpartnership.org.

11 'Open Government Declaration' OGP, above n 10.

12 OGP, above n 10.

13 OGP, above n 10.

14 OGP, above n 10.

15 See 'World Bank Open Data' World Bank data.worldbank.org.

16 See Steve Clayton 'Microsoft's Open Government Data Initiative with Windows Azure' (11 May 2009) Microsoft Developer blogs.msdn.microsoft.com; Marius Oiaga 'Windows Azure Powers Microsoft Open Government Data Initiative' (7 May 2009) Softpedia news.softpedia.com.

17 See the discussion below, Section 3.2.

18 See Frederik Zuiderveen Borgesius, Jonathan Gray and Mireille van Eechoud 'Open Data, Privacy, and Fair Information Principles: Towards a Balancing Framework' (2015) 30 Berkley Tech LJ 2073 at 2081. 
of natural or social phenomena or human behaviours. ${ }^{19}$ A number of nonprofit organisations, such as the Open Data Institute, Open Knowledge Foundation and the Sunlight Foundation, have also actively taken part in the OGD movement in different ways. ${ }^{20}$

OGD policy involves various legal issues, ranging from personal data protection, ${ }^{21}$ citizens' right of access to government information or freedom of information, ${ }^{22}$ the attribution of legal liability ${ }^{23}$ and appropriate parties to release and receive government data. ${ }^{24}$ Intellectual property (IP) and licensing thereof has both been viewed as a cornerstone for OGD, in terms of structuring the government-user relationship ${ }^{25}$ and, from a cynical perspective, as one of the main obstacles to the release of governments' data in accordance with the OGD ideology. ${ }^{26}$ Government agencies may delay the release of the data because they are uncertain about the best licensing arrangement of the data they hold. Entrepreneurs may hesitate to use or reuse government data if there is no reliable licensing or clear legal arrangement governing it. ${ }^{27}$ Tim Berners-Lee, inventor of the World

19 See Monino and Sedkaoui, above n 8, at 30-33 and 38; Michael Chui, Diana Farrell and Steve Van Kuiken 'Generating Economic Value Through Open Data' in Brett Goldstein and Lauren Dyson (eds) Beyond Transparency: Open Data and the Future of Civic Innovation (Code for America, San Francisco, 2013) 163 at 163; Joel Gurin 'Big Data and Open Data: How Open Will the Future Be?’ (2015) 10 IS JL Poly for Info Socy 691 at 699-700 (2015); Hardy and Maurushat, above n 2, at 30-31; Ubaldi, above n 2, at 5-7; see also Maureen K Ohlhausen The Social Impact of Open Data (Federal Trade Commission, 23 July 2014) (addressing the relationship between Big Data and OGD from the perspective of the United States Federal Trade Commission).

20 See Lee, Cyganiak and Decker, above n 5, at 28-31.

21 See Gurin, above n 5, at 183-195, 232; Micah Altman and others 'Towards a Modern Approach to Privacy-Aware Government Data Releases' (2015) 30 Berkley Tech LJ 1976 at 2006-2010, 20482059; Hardy and Maurushat, above n 2, at 34; Jeff Jonas and Jim Harper 'Open Government: The Privacy Imperative' in Daniel Lathrop and Laurel Ruma (eds) Open Government: Collaboration, Transparency, and Participation in Practice (O’Reilly Media, 2010); Borgesius, Gray and van Eechoud, above n 18, at 2086-2093, 2107-2114, 2125-2129; Mashael Khayyat and Frank Bannister 'Open Data Licensing: More Than Meets the Eye' (2015) 20 Info Poly 231 and 244-245; Zuiderwijk and Janssen n 5, at 22, 26; Lee, Cyganiak and Decker, above n 5, at 63-65; Ubaldi, above n 2, at 43.

22 See Tauberer, above n 2, at 87-89, 125; Jeffrey D Rubenstein 'Hacking FOIA: Requests to Drive Government Innovation' in Brett Goldstein and Lauren Dyson (eds) Beyond Transparency: Open Data and the Future of Civic Innovation (Code for America, San Francisco, 2013) 81; Gurin, above n 19, at 700-701; Marcowitz-Bitton, above n 3, at 419-423; Lee, Cyganiak and Decker, above n 5, at 21; Ubaldi, above n 2, at 4-5, 37.

23 Zuiderwijk and Janssen, above $\mathrm{n}$ 4, at 22.

24 See David Robinson and others 'Government Data and the Invisible Hand' (2009) 11 Yale JL \& Tech 160 (arguing that private sector, commercial or non-profit organisations, rather than the government, are better suited to deliver OGD).

25 See Ubaldi, above n 2, at 37.

26 See Khayyat and Bannister, above n 21, at 232; Janssen, above n 2, at 452 (noting that quite a few French Governments had been struggling with licensing policies toward OGD).

27 Ubaldi, above n 2, at 11 . 
Wide Web, provided a 5-Star Scheme to evaluate the degree of dataset reusability. ${ }^{28}$ The scheme's initial 1 -Star level sets the most fundamental requirement for OGD, which is that data should be accessible online under an open licence. ${ }^{29}$ However, this scheme neither illustrates what is an appropriate open licence for OGD, nor explains why an open licence matters for OGD. In other words, this scheme advocates for the implementation of open licensing for OGD without further definition of this type of licence and its association with OGD.

This chapter focuses on legal issues associated with OGD licences in the Greater China region - namely, Hong Kong, Mainland China and Taiwan. Different government agencies with different policy goals have set different legal terms under which they will release their data. These terms reflect policy considerations that differ from those contemplated in business transactions or shared in typical commons scenarios, such as free or open source software communities. ${ }^{30}$ They also concern some fundamental IP issues that are not covered by, or analysed in depth in, the current literature.

The aim of this chapter is to provide a comprehensive legal analysis of open data licences or terms in Hong Kong, mainland China and Taiwan. This study argues that the choice and design of an open data licence forms an important element of a government's information policy. Part 2 introduces the concept and characteristics of OGD, which emphasises citizens' easy and timely access to government data. The features associated with OGD have begun to form an increasingly universal principle adhered to around the world. Part 3 identifies the primary policy goals of OGD, which include the enhancement of governmental transparency, accountability, public participation, the improvement of democracy and public service quality and the advancement of innovation and economic development. These policy goals should be the deciding factors in the design and choice of licence. Part 4 explores the licences and terms design for OGD in Hong Kong, mainland China and Taiwan. Part 5 examines the major legal issues pertaining to the licensing of OGD in the three jurisdictions mentioned above. Part 6 concludes the findings of this chapter.

\footnotetext{
28 James G Kim and Michael Hausenblas 'By Example ...' 5 Star Open Data 5 stardata.info.

29 Ibid.

30 See Jyh-An Lee 'New Perspectives on Public Goods Production: Policy Implications of Open Source Software' (2008) 9 Vand J Ent \& Tech L 45 at 50-53; Molly Shaffer Van Houweling 'The New Servitudes' (2008) 96 Geo LJ 885 at 925-926.
} 


\section{The Concept of Open Data}

OGD, sometimes referred to as open Public Sector Information (PSI), ${ }^{31}$ represents policies or practices that make data held by the public sector digitally available and accessible for reuse or redistribution for free or at a nominal cost. According to the European Union (EU) Directive on the Re-Use of Public Sector Information, '[o]pen data policies ... encourage the wide availability and re-use of public sector information for private or commercial purposes, with minimal or no legal, technical, or financial constraints'. ${ }^{32}$ Commentators may link the open data movement to other similar movements, in which information is released and widely disseminated by digital technologies and through the internet. ${ }^{33}$ Those movements include open access, open educational resources, open standard and free or open source software initiatives. ${ }^{34}$

A number of organisations and individuals have provided their own definitions of, or criteria for, open data. For example, a working group led by Carl Malamud, a renowned advocate for open internet and OGD, first suggested eight principles for open data in December 2007. ${ }^{35}$ These principles include complete, primary, timely, accessible, machine processable, non-discriminatory, non-proprietary, and licence-free. ${ }^{36}$

31 Zuiderwijk and Janssen, above $\mathrm{n}$ 5, at 17 .

32 Amending Directive 2003/98/EC on the Re-Use of Public Sector Information [2013] OJ L175/1 [EU Amending Directive]; see Hardy and Maurushat, above n 2, at 30; Tauberer, above n 2, at 95; Lee, Cyganiak and Decker, above n 4, at 4; Ubaldi, above n 2, at 6; Gurin, above n 5, at 9 ('Open Data can best be described as accessible public data that people, companies, and organizations can use to launch new ventures, analyze patterns and trends, make data-driven decisions, and solve complex problems'); Borgesius, Gray and van Eechoud, above n 18, at 2075 ('[o]pen government data refers to data released by public sector bodies, in a manner that is legally and technically reusable'); but see Luca Leone 'Open Data and Food Law in the Digital Era: Empowering Citizens Through ICT Technology' (2015) 10 Eur Food \& Feed L Rev 356 at 358 (claiming that there is no generally accepted definition of open data or OGD).

33 See Yu and Robinson, above n 6, at 187-188; Sanz, above n 8, at 3-5 and 8-11 (describing a series of openness movements enabled by the internet, including the free/open source software movement, and their relations to OGD).

34 See Tauberer, above n 2, at 12-13, 93; Scassa, above n 5, at 1779-1780; Yu and Robinson, above n 6, at 187-188; Weinstein and Goldstein, above n 6, at 40 (noting that OGD represents 'a new alignment of open source and transparency').

35 Open Gov Data 'The Annotated 8 Principles of Open Government Data' (8 December 2007) Open Gov Data opengovdata.org.

36 Open Gov Data, above n 35; Tauberer, above n 2, at 187-188; Khayyat and Bannister, above n 21, at 242; Ubaldi, above n 2, at 8 . 
Open Knowledge International (OKI), a British non-profit network advocating for free access to, and the sharing of, information globally, defines open data as 'data that can be freely used, re-used and redistributed by anyone - subject only, at most, to the requirement to attribute and [sic] sharealike'. ${ }^{37}$ According to OKI's definition, there should be no discrimination in regard to different uses of government data. ${ }^{38}$ Therefore, "non-commercial" restrictions that would prevent "commercial" use, or restrictions of use for certain purposes (e.g., only in education), are not allowed'. 39

Finally, the Sunlight Foundation has published its Open Data Policy Guidelines to illustrate OGD best practices. ${ }^{40}$ The International Open Data Charter, a collaboration between governments based on the G8 Open Data Charter, identifies six principles of open data: open by default; timely and comprehensive; accessible and usable; comparable and interoperable; for improved governance and citizen engagement; and for inclusive development and innovation. ${ }^{41}$

In sum, most open data advocates concur on the principles of timeliness, comprehensiveness and that the data must be openly accessible. ${ }^{42}$ In addition, two other noteworthy principles, 'open by default' and 'open format', are supported by most open data advocates. These are discussed below.

\subsection{Open by Default}

Many believe that it is a general principle that government data should be openly and freely available online, whereas the non-disclosure of government data should be an exception. A government's proactive disclosure of data is essential to its transparency and democratic governance. ${ }^{43}$ In other words, governments should open their data by default unless there is a compelling reason, such as national security or privacy protection, to keep the data confidential. ${ }^{44}$ This principle is

37 'What is Open Data' Open Data Handbook opendatahandbook.org.

38 Open Data Handbook, above n 42.

39 Open Data Handbook, above n 42.

40 'Open Data Policy Guidelines' Sunlight Foundation sunlightfoundation.com.

41 'Principles' Open Data Charter opendatacharter.net.

42 See Tauberer, above n 2, at 98-99 and 115; Ubaldi, above n 2, at 24.

43 Borgesius, Gray and van Eechoud, above n 18, at 2084.

44 See Gurin, above n 5, at 219. 
recognised in the G8 Open Data Charter ${ }^{45}$ and in the open data policies of the EU and the United Kingdom. ${ }^{46}$ It can also be found in New York City's Technical Standards Manual, which states that: ${ }^{47}$

[a]ll public data sets must be considered open unless they contain information designated as sensitive, private, or confidential as defined by the Citywide Data Classification Policy or information that is exempt pursuant to the Public Officers' Law, or any other provision of a federal or state law, rule or regulation or local law.

\subsection{Open Format}

Government data should be made available in formats that are suitable for all types of use. ${ }^{48}$ The data should be in formats that are machinereadable, downloadable, usable and distributable. ${ }^{49}$ Such formats are typically open or non-proprietary industrial protocols and formats. ${ }^{50}$ Put differently, " $[\mathrm{a}] \mathrm{n}$ open format is one that is platform independent, machine readable, and made available to the public without restrictions that would impede the re-use of that information'. ${ }^{51}$ Extensible Markup Language (XML) is an example of open format, enabling interoperability of data from diverse sources. ${ }^{52}$

In Tim Berners-Lee's Five-Star Open Data Scheme, 'using non-proprietary formats' is at the Three-Star level. ${ }^{53}$ An open format can effectively promote the analysis and reuse of data. ${ }^{54}$ The Obama Administration endorsed releasing government data in 'computer-readable' forms. ${ }^{55}$ Similarly, in the Open Government Declaration created in

45 Open Data Charter, above $\mathrm{n} 41$.

46 See Gurin, above n 5, at 219.

47 New York City Department of Information Technology and Telecommunications NYC Open

Data: Open Data Policy and Technical Standards Manual (November 2016) at 3.4.1.

48 Tauberer, above $\mathrm{n} 2$, at 99.

49 See Raines, above n 6, at 324; Ubaldi, above n 2, at 24.

50 Tauberer, above n 2, at 99; see also Teresa Scassa and Robert J Currie 'New First Principles? Assessing the Internet's Challenges to Jurisdiction' (2011) 42 Geo J Intl L 1017 at 1067 (noting that efforts to control format in the OGD settings are fading).

51 Peter R Orszag Memorandum for the Heads of Executive Departments and Agencies (Executive Office of the President Office of Management and Budget, Memorandum 10-16, 8 December 2009).

52 See Leone, above n 32, at 358.

53 Kim and Hausenblas, above $\mathrm{n} 28$. The scheme measures open data in terms of how well data is integrated into the web: Five Star is the highest level and One Star is the minimal level. See Tim Berners-Lee 'Linked Data'(18 June 2009) www.w3.org.

54 Tauberer, above $\mathrm{n} 2$, at 100-101.

55 'Technology' Obama White House Archive obamawhitehouse.archives.gov. 
September 2011, the United States and seven other signatory countries agreed to 'provide high-value information, including raw data, in a timely manner, in formats that the public can easily locate, understand and use, and in formats that facilitate reuse..$^{56}$

\section{Policy Goals Underlying Open Data}

OGD brings important social, economic and democratic value to society. ${ }^{57}$ Likewise, it can promote both public and private interests. ${ }^{58}$ An EU Directive on the Re-Use of Public Sector Information further highlights the value of open data policies: 59

Open data policies ... which promote the circulation of information not only for economic operators but also for the public, can play an important role in kick-starting the development of new services based on novel ways to combine and make use of such information, stimulate economic growth and promote social engagement.

OGD policies are tasked with changing the way people run governments and do business via freely available government data. ${ }^{60}$ Therefore, the aim of some OGD policies is to build an ecosystem with multiple functions. Identifying policy goals for OGD and setting priorities are also critically important for the design of data governance and relevant legal structures, including licences. In Part 3, I briefly analyse the policy goals underlying OGD.

57 See Peter Conradie and Sunil Choenni 'On the Barriers for Local Government Releasing Open

Data' (2015) 31 Government Information Quarterly 10 at 10.

58 See Gurin, above n 5, at 218.

59 EU Amending Directive, above n 32.

60 Gurin, above n 5, at 9. 


\subsection{Transparency and Accountability}

OGD promotes the transparency of government and the policymaking process, which underpins accountability and democracy. ${ }^{61}$ Transparency involves the disclosure of actions taken by the public sector. ${ }^{62}$ Government data can definitely shed light on government activities. Some government data, such as that pertaining to public spending, distribution of revenue and subsidy, is critically important for government accountability. ${ }^{63}$ Therefore, by enabling the monitoring of government activities, open data can help reduce corruption. ${ }^{64}$

The former Obama Administration identified its open data policy goal as increasing transparency, participation and collaboration ${ }^{65}$ which will eventually advance the quality and efficiency of the services provided by the government. ${ }^{66}$ Likewise, the French Government's OGD policy aims to promote government accountability and make good use of the 'collective intelligence of its citizens'. ${ }^{67}$ The Australian Government similarly acknowledged how public access and the reuse of government information could enhance public participation and democracy. ${ }^{68}$ The World Bank stated that open data 'encourages greater citizen participation in government affairs' and 'supports democratic societies'. ${ }^{69}$ Therefore, OGD has been viewed as a tool to advance public scrutiny, political

61 See Lee, Cyganiak and Decker, above n 5, at 4; Hardy and Maurushat, above n 2, at 33; Tauberer, above n 2, at 132; Chui, Farrell and Van Kuiken, above n 19, at 163-164; Janssen, above n 2, at 446; Leone, above n 32 at 356 and 358; Marcowitz-Bitton, above n 3, at 413; Scassa, above n 5, at 1760; Veljković, Bogdanović-Dinić and Stoimenov, above n 6, at 280; Yu and Robinson, above n 6, at 196-197; Zuiderwijk and Janssen, above n 5, at 17; Ubaldi, above n 2, at 4 and 11-12; Weinstein and Goldstein, above n 6, at 46; Judith Bannister 'Open Government: From Crown Copyright to the Creative Commons and Culture Change' (2011) 34(3) UNSW LJ 1080 at 1089 (stating that open access to government information improves transparent decision-making and the quality of democracy); Tiago Peixoto 'The Uncertain Relationship Between Open Data and Accountability: A Response to Yu and Robinson's the New Ambiguity of "Open Government" (2013) 60 UCLA L Rev Discourse 200 at 202 and 207 (arguing that open date enables transparency, which may lead to accountability).

62 Peixoto, above n 61, at 203.

63 Borgesius, Gray and van Eechoud, above n 18, at 2083.

64 See Marcowitz-Bitton, above n 3, at 416; 'Starting an Open Data Initiative' World Bank opendatatoolkit.worldbank.org.

65 Borgesius, Gray and van Eechoud, above n 18, at 2083-2084; Sanz, above n 8, at 10.

66 Hardy and Maurushat, above n 2, at 32; Orszag, above n 51, at 1; Scassa, above n 5, at 1760; Yu and Robinson, above n 6, at 196 and 201; Zuiderwijk and Janssen, above n 5, at 17; Borgesius, Gray and van Eechoud, above n 18, at 2085-2086 (illustrating how open data promotes public sector efficiency and improves the quality of public service); Peixoto, above n 61, at 202 (arguing that OGD enables participation, which fosters better services and policies).

67 Borgesius, Gray and van Eechoud, above n 18, at 2083.

68 Bannister, above n 61, 1091-1092.

69 World Bank, above n 64. 
accountability, ${ }^{70}$ participation and the quality of government services. Ideally, these features will combine to improve the governance of, and trust in, the public sector. ${ }^{71}$

\subsection{Economic Development}

OGD has been described as constituting a crucial strategy to build a 'datadriven economy'. ${ }^{72}$ The immense volume and diversity of government data may bring great commercial value to enterprises. ${ }^{73}$ Put more clearly, OGD is an abundant free resource that fuels a wide range of new innovative products, apps, services and business models associated with data reuse and analysis. ${ }^{74}$ Additional value is then created by means of crowdsourcing, user tracking, and data analytics' ${ }^{75}$ Various commercial uses of government data may further encourage economic development. ${ }^{76}$ In other words, a properly designed OGD policy can unlock the value of PSI to the public sector. ${ }^{77}$

On 9 May 2013, when the United States Office of Management and Budget and the Office of Science and Technology Policy announced its Open Data Policy, President Obama signed an Executive Order to promote OGD and stated that: ${ }^{78}$

[Open data can] fuel more private sector innovation ... And talented entrepreneurs are doing some pretty amazing things with it ... Starting today, we're making even more government data available online, which

\footnotetext{
70 Yu and Robinson, above n 6, at 182.

71 Open Data Charter, above n 41.

72 Leone, above n 32, at 358.

73 See Leone, above n 32, at 356; Marcowitz-Bitton, above n 3, at 413; Scassa, above n 5, at 17731774 (describing the commercial value of transit data); Gurin, above n 5, at 693-696.

74 See Gurin, above n 5, at 23-35 and 218-219; Chui, Farrell and Van Kuiken, above n 19, at 163 and 168; Janssen, above n 2, at 446; Marcowitz-Bitton, above n 3, at 416; Conradie and Choenni, above $\mathrm{n}$ 57, at 10 (stating that 'the release of [government] data for a broader use may give a boost to the creative industry, which in return leads to innovative applications and techniques').

75 Michael Halberstam 'Beyond Transparency: Rethinking Election Reform from an Open Government Perspective’ (2015) 38 Seattle UL Rev 1007 at 1028.

76 See Lee, Cyganiak and Decker, above n 5, at 4; Scassa, above n 5, at 1760-1761; Zuiderwijk and Janssen, above n 5, at 17; Gurin, above n 5, at 217 (stating that open government datasets 'can have a powerful impact for the public good and economic growth'); Gianluca Misuraca, Fransesco Mureddu and David Osimo 'Policy-Making 2.0: Unleashing the Power of Big Data for Public Governance' in Milo Gascó-Hernández (ed) Open Government: Opportunities and Challenges for Public Governance (2014) 171 in Christopher G Reddick (series ed) Public Administration and Information Technology (Springer, 2014) vol 4 at 171 (describing the benefit brought by OGD in the commercial field).

77 See Borgesius, Gray and van Eechoud, above n 18, at 2080.

78 The White House Office of the Press Secretary, above n 4.
} 
will help launch even more new startups. And we're making it easier for people to find the data and use it, so that entrepreneurs can build products and services we haven't even imagined yet.

The European Commission has also highlighted the potential for significant economic gains to come from OGD. ${ }^{79}$ Similarly, both the United Kingdom ${ }^{80}$ and Australian ${ }^{81}$ governments have stated that OGD could greatly benefit the economy. A number of studies have estimated that the economic value brought by OGD in some countries will exceed hundreds of millions, or even trillions, of dollars. ${ }^{82}$ For example, the McKinsey Global Institute estimated that open data could unlock an economic value of US\$3-5 trillion a year across seven sectors in the United States. ${ }^{83}$ In summary, OGD can form an important part of a government's economic policy when it comes to fostering innovation and economic development.

\section{Standardised OGD Licences in the Greater China Region}

Some OGD advocates believe that true open data should be free from licence restrictions $;{ }^{84}$ others claim that without specific open licences, it is too costly for users to search and negotiate with data publishers. ${ }^{85}$ For those who believe licences are necessary for OGD, the consensus is that the licences, or terms and conditions, should facilitate optimal access to the underlying data. ${ }^{86}$ Government agencies may choose click-

79 Zuiderwijk and Janssen, above n 5, at 17.

80 See Gurin, above n 5, at 9; National Archives, above n 2, at 6; Janssen, above n 2, at 451.

81 Bannister, above $\mathrm{n}$ 61, at 1091.

82 See Borgesius, Gray and van Eechoud, above n 18, at 2082; Lee, Cyganiak and Decker, above n 5, at 18-19; Chui, Farrell and Van Kuiken, above n 19, at 166; Marcowitz-Bitton, above n 3, at 424; Ubaldi, above n 2, at 15 .

83 James Manyika and others 'Open Data: Unlocking Innovation and Performance with Liquid Information' (October 2013) McKinsey \& Company www.mckinsey.com.

84 See Tauberer, above n 2, at 106 and 144-145; Yu and Robinson, above n 6, at 196; Yochai Benkler 'Commons and Growth: The Essential Role of Open Commons in Market Economies (Book Review)' (2013) 80 U Chi L Rev 1499 at 1551 (claiming that OGD is subject to no constraint).

85 See, for example, Lee, Cyganiak and Decker, above n 5 at 6; Federico Morando 'Legal Interoperability: Making Open Government Data Compatible with Businesses and Communities' (2013) 4 Italian J Libr Archives \& Info Sci 441 at 442 (introducing the viewpoint that 'the distribution of data also requires ... licensing').

86 Ruth Okediji 'Government as Owners of Intellectual Property? Considerations for Public Welfare in the Era of Big Data' (2016) 18 Vand J Ent \& Tech L 331 at 336. 
use or standardised licences, such as a Creative Commons licence, ${ }^{87}$ or they may choose to develop their own licensing terms. ${ }^{88}$ The primary advantages of using standardised licences are saving costs associated with creating a bespoke licence, achieving order and efficiency, and achieving interoperability between licences. ${ }^{89}$ The use of standardised licences does not necessarily equate to harmonised copyright laws. Standardised licences aim to help copyright owners, including governments, license their content easily and efficiently, whereas international harmonisation proposals, such as the Asian Pacific Copyright Code proposed by Adrian Sterling and the Asian Pacific Copyright Association, aim to implement copyright systems in different jurisdictions and, eventually, create a mutually applicable dispute resolution system. ${ }^{90}$ In this section, I introduce the licences or terms of use adopted in Hong Kong, Mainland China and Taiwan and analyse their similarities and dissimilarities.

\subsection{Hong Kong}

In 2014, the former Financial Secretary of Hong Kong, John Chunwah Tsang, announced the Government's plan to make Hong Kong a smart city. ${ }^{91}$ Among others, an important initiative was to make all government information available online. ${ }^{92}$ Consequently, the Office of the Government Chief Information Officer (OGCIO) has overhauled its open data portal to facilitate a wide range of value-added data reuse. ${ }^{93}$ The revamped portal, data.gov.hk, came into existence in March 2015 and covers 18 dataset categories. ${ }^{94}$ It is estimated that there are more than

87 See Marcowitz-Bitton, above n 3, at 439; Lee, Cyganiak and Decker, above n 5, at 67.

88 See Food and Drug Administration (FDA) 'Terms of Services' (22 March 2014) Open FDA open.fda.gov.

89 See Khayyat and Bannister, above n 21, at 238; Marcowitz-Bitton, above n 3, at 434; Naomi Korn and Charles Oppenheim 'Licensing Open Data: A Practical Guide' (June 2011) Discovery discovery.ac.uk at version 2.0; Kent Mewhort 'Creative Commons Licenses: options for Canadian Open Data Providers' (1 June 2012) CIPPIC: Canadian Internet Policy and Public Interest Clinic cippic.ca (noting the benefit of interoperability brought by $\mathrm{CC}$ licences).

90 Adrian Sterling 'Asian Pacific Copyright Code' this volume.

91 John Chun-wah Tsang, Hong Kong Financial Secretary '2014-15 Budget Speech'(Legislative Council of the Hong Kong Special Administrative Region of the People's Republic of China, 26 February 2014).

92 Chun-wah Tsang, above n 91.

93 'Open Data' Legislative Council of the Hong Kong Special Administrative Region of the People's Republic of China www.legco.gov.hk.

94 Data.gov.hk data.gov.hk. 
6,000 datasets on this portal. In the same year, Hong Kong was ranked 34th among 122 countries and areas in the 2015 Global Open Data Index released by OKI. ${ }^{95}$

Under the 'Terms and Conditions of Use' found on the portal, the OGCIO outlines two provisions to regulate the licensing of government data. ${ }^{96}$ Article 8 stipulates: (1) what a user can and cannot do and (2) the government's disclaimer regarding any liability arising from the use of the subject data. ${ }^{97}$ Users 'are allowed to browse, download, distribute, reproduce, hyperlink to, and print in their original format the Data for both commercial and non-commercial purposes on a free-ofcharge basis' ${ }^{98}$ Users should 'reproduce and distribute the Data accurately, fairly and sufficiently' ${ }^{99}$ Moreover, users should not only attribute the source from the government, but also acknowledge the government's IP ownership over the data. ${ }^{100}$ Article 9 defines the 'commercial purpose' of art $8 .{ }^{101}$ These two provisions, especially art 8, play a crucial role in regulating the legal relations between the Hong Kong Government and data users.

\subsection{Mainland China}

China's Premier Li Keqiang stated in March 2015 that government data should be public wherever possible 'unless it is relevant to national security and privacy'. ${ }^{102}$ Shanghai and Beijing were the first cities to begin OGD policies in mainland China. ${ }^{103}$ The National Bureau of Statistics was the first central government agency that released OGD, ${ }^{104}$ followed

95 'Place overview' Global Open Data Index index.okfn.org.

96 'Terms and Conditions of Use' Data.gov.hk data.gov.hk.

97 At 8 .

98 At 8 .

99 At 8 .

100 At 8: you shall identify clearly the source of the Data and acknowledge the Government ownership of the intellectual property rights in the Data and in all copies thereof including but not limited to paper copies, digital copies and copies placed on other websites.'

101 At 8-9.

102 Eleanor Ross 'Why Open Data Doesn't Mean Open Government' The Guardian (online ed, United Kingdom, 2 December 2015).

103 Joel Gurin 'The People’s Republic of Open Data?' (11 December 2014) Open Data Now www. opendatanow.com.

104 National Bureau of Statistics of China data.stats.gov.cn. 
by the State Intellectual Property Office (SIPO)'s open patent database. ${ }^{105}$ A number of local governments, such as Zhejiang Province, ${ }^{106}$ Qingdao City ${ }^{107}$ and Zhanjiang City, ${ }^{108}$ have also established OGD portals.

Most Chinese government agencies building OGD portals do not provide terms of use or licensing agreements for users. As of March 2017, only the City of Beijing, ${ }^{109}$ Zhejiang Province ${ }^{110}$ and Qingdao City ${ }^{111}$ have statements on legal rights and obligations regarding the use of their OGD. Beijing uses the term 'Disclaimer', whereas Zhejiang uses the term 'Statement of the Website'. ${ }^{112}$ Beijing's Disclaimer covers not only a disclaimer made by the government, but also the users' obligations with regard to the use of government data. ${ }^{113}$ Qingdao provides two documents to regulate users' use of the data, namely a 'disclaimer' ${ }^{114}$ and the 'Licence Agreement of Qingdao City's Open Data Portal'. ${ }^{115}$

In the City of Beijing's and Qingdao's Disclaimers, users are granted the right to use the OGD for free, ${ }^{116}$ but Beijing does not allow users to transfer the data to any third party. ${ }^{117}$ Qingdao's Disclaimer similarly provides for free use of the data but reserves the right to charge users in the future. ${ }^{118}$ Qingdao's 'License Agreement of Qingdao City's Open Data Portal' provides that users are licensed to 'download, reproduce, and distribute' the data and initiate commercial or non-commercial development, based on the data released by the portal. ${ }^{119}$ However, Qingdao's License Agreement prohibits users from charging any third party for the data obtained from the portal. ${ }^{120}$

105 State Intellectual Property Office of the PRC patdata.sipo.gov.cn.

106 Zhejiang Provincial Government Portal data.zjzwfw.gov.cn.

107 Open Data of Qingdao Government qingdao.gov.cn/data.

108 Zhanjiang Data Service Network data.zhanjiang.gov.cn.

109 'Disclaimer' BJ Data www.bjdata.gov.cn.

110 'Statement of the Website' Zhejiang Provincial Government Portal www.zjzwfw.gov.cn.

111 Open Data of Qindao Government, above n 107.

112 'Disclaimer' BJ Data, above n 109; 'Statement of the Website' Zhejiang Provincial Government Portal, above n 110.

113 'Disclaimer' BJ Data, above n 109.

114 'Disclaimer' Open Data of Qingdao Government, above n 107.

115 'Licence Agreement of Qingdao City's Open Data Portal' Open Data of Qingdao Government, above $\mathrm{n} 107$.

116 'Disclaimer' BJ Data, above n 109; Open Data of Qingdao Government, above n 107.

117 'Disclaimer' BJ Data, above n 109.

118 'License Agreement of Qingdao City's Open Data Portal' Open Data of Qingdao Government, above $\mathrm{n} 107$.

119 'License Agreement of Qingdao City's Open Data Portal'.

120 'License Agreement of Qingdao City's Open Data Portal'. 
Like many other OGD licences, Beijing's Disclaimer requires users to attribute the portal as the source. ${ }^{121}$ It also includes a disclaimer indicating that the government is not responsible for the integrity, accuracy or whether the underlying data is up to date. ${ }^{122}$ Similar disclaimers can also be found in Qingdao's Disclaimer ${ }^{123}$ and Zhejiang's 'Statement of the Website. ${ }^{124}$ Beijing's Disclaimer further stipulates that the application developed by users should be approved by the government and that the government has the power to delete or block the application afterwards if the application is found to violate the law. ${ }^{125}$ Zhejiang has made it clear in its 'Statement of the Website' that the government owns copyright in the text, picture, audio, software and other forms of data from its portal. ${ }^{126}$ The Statement provides that users are required to obtain a licence from the government for the use of data. ${ }^{127}$ However, there is no standardised licence agreement on the website.

\subsection{Taiwan}

The Taiwan Government released a Cabinet's executive resolution in November 2012 regarding OGD policy, followed by the other detailed rules, such as 'Open Government Data Operating Principle for Agencies of the Executive Yuan', the 'Essential Requirements for Government Open Data Datasets' and the 'Regulations for the Use of the Government Open Data Platform'. ${ }^{128}$ In 2013, the National Development Council established the Government Open Data Platform, which collects various open government datasets from both central and local government agencies. ${ }^{129}$ In November 2013, the Industrial Development Bureau, under the Taiwan Ministry of Economic Affairs, released and started to implement the 'Open Data Application Promotion Plan'. ${ }^{130}$ Taiwan ranked number one among 122 jurisdictions in the 2015 Open Data Index, released by the Open Knowledge Foundation (OKFN). ${ }^{131}$

121 'Disclaimer' BJ Data, above n 109.

122 'Disclaimer' Open Data of Qingdao Government, above n 107.

123 'Disclaimer'.

124 'Statement of the Website' Zhejiang Provincial Government Portal, above n 110.

125 BJ Data above n 109.

126 'Statement of the Website' Zhejiang Provincial Government Portal, above n 110.

127 'Statement of the Website'.

128 'e-Government position: An Outline of the Government Open Data Promotion Situation in Taiwan' National Development Council (NDC) www.ndc.gov.tw.

129 See Data.gov.tw data.gov.tw.

130 Industrial Development Bureau Overview of Open Data Development in Taiwan (Ministry of Economic Affairs, Taiwan, November 2013).

131 Global Open Data Index, above n 95. 
The Taiwan Government published the 'Open Government Data License, version $1.0^{\prime}$ on 27 July 2015, for the release of OGD. ${ }^{132}$ The licence includes seven articles, which provide the definitions of 'data providing organization', 'user' and 'open data.. ${ }^{133}$ The licence grants users with a 'perpetual, worldwide, non-exclusive, irrevocable, royalty-free copyright licence to reproduce, distribute, publicly transmit, publicly broadcast, publicly recite, publicly present, publicly perform, compile, adapt to the Open Data provided for any purpose..$^{134}$ Like many OGD licences, the licence requires users to attribute the data source ${ }^{135}$ and provides a disclaimer for government agencies that release data. ${ }^{136}$ In May 2016, the licence was approved by the Open Definition Advisory Council in the OKI as conforming to its open definition and was included in its conformant licence list. ${ }^{137}$

\section{Legal Analysis of the OGD Licences}

The enforceability of a public (open source) licence was recognised by the United States courts in Jacobsen $v$ Katzer, in which the United States Federal Circuit acknowledged the value that open source projects bring to society and reaffirmed the copyright holders' freedom to license their copyright on their own terms. ${ }^{138}$ The open licences or terms of use associated with OGD, introduced in the previous section, share a number of similarities, though differ in many ways. An attribution requirement and a governmental disclaimer are quite common. In this section, a number of important issues arising from the design of a licence, or its terms and conditions, will be analysed.

\subsection{Charges}

'Free of charge' is a principle that is normally found in OGD policies. For example, the Taiwan Government has made it clear in its 'Open Government Data License, version 1.0' that the ' $\mathrm{t}] \mathrm{he}$ Data Providing

132 'Open Government Data License: version 1.0’ (27 July 2015) NDC data.gov.tw.

133 At 1 .

134 At 2 .

135 At 3 .

136 At 6 .

137 Herb Lainchbury 'Announcement: 'Open Government Data License Taiwan 1.0' Approved' (2 May 2016) Open Knowledge International discuss.okfn.org.

138 Jacobsen v Katzer 535 F 3d 1373 (Fed Cir 2008) at 1381-1382. 
Organization grants User a perpetual, worldwide, non-exclusive, irrevocable, royalty-free copyright license'. ${ }^{139}$ All the licences or terms associated with OGD in the Greater China regions, introduced in the previous section, likewise state that the data is provided free from any royalty. Therefore, users or licensees do not need to pay for the licensed materials.

Nonetheless, as mentioned previously, in its Disclaimer, the City of Qingdao reserves the right to charge users in the future. ${ }^{140}$ From a comparative perspective, the United Kingdom's Charged Licence charges users to use government data. A reasonable explanation for such a difference is that the United Kingdom Government designed the Charged Licence and the government has certain practical considerations to reflect on, including the cost of implementing open data policies. It should also be noted that the United Kingdom Government has deliberately placed two restrictions on the adoption of the Charged Licence: (1) this licence is an exception; and (2) charges should be limited to the costs arising from 'the re-use of information'. ${ }^{141}$ This exception, though not yet implemented, is probably designed to retain more financial flexibilities for public agencies with regard to some unique types of data.

Charging a reasonable fee for the use of government data is also permitted in the EU PSI Directive. ${ }^{142}$ According to the Directive, the fee must be limited to 'the marginal costs incurred for their reproduction, provision and dissemination' and the charges 'shall not exceed the cost of collection, production, reproduction and dissemination, together with a reasonable return on investment'. ${ }^{143}$ Although both the Charged Licence and the EU PSI Directive allow charging for the use of government data, the EU PSI Directive conflicts with the public interest concerns of OGD policy. The Directive permits using open data as a tool to collect 'a reasonable return on investment' in addition to 'the cost of collection, production, reproduction and dissemination'. ${ }^{144}$ However, since the generally accepted OGD policy's goal is to promote transparency, accountability, participation and economic development, ${ }^{145}$ open data should not be used as a finance

139 'Open Government Data Licence: version 1.0’ Data.gov.tw data.gov.tw at 2.1 (emphasis added).

140 Open Data of Qingdao Government, above n 107.

141 National Archives, above n 2, at 4.

142 EU Amending Directive, above n 32.

143 Article 6(3).

144 Article 6(3).

145 See above, Part 3. 
tool to benefit the government. ${ }^{146}$ Therefore, the charges provision in the PSI Directive is obviously not the best practice for OGD policy. For the same token, the reservation provision, with regard to charges in Qingdao's Disclaimer, may create unnecessary uncertainties for OGD users.

\subsection{Restriction of Data Use}

In order to maximise the use of government data, a substantial segment of the open data community suggests that licensing terms should be the least restrictive or subject to minimal constraints. ${ }^{147}$ Nevertheless, 'minimal constraint' does not mean no constraints at all. ${ }^{148}$ Accordingly, what constitutes 'minimal constraint' becomes an issue when the policy goal is to maximise the use of government data. Attribution is the most common restriction in public licences, and is discussed in section 5.5 below. Since fostering innovation, new business models and economic development are some of the primary policy goals of OGD, restrictions other than attribution also need to be scrutinised.

Based on the study of licences and other terms applying to users of OGD in the Greater China region, those in Mainland China tend to be more restrictive than those in Hong Kong and Taiwan. For example, Beijing's Disclaimer prohibits users from transferring the data to third parties. ${ }^{149}$ However, many new applications associated with OGD involve the transfer of government data. Qingdao's License agreement prohibits users from charging any third party for the data obtained from the portal. ${ }^{150}$ It is unclear from Qingdao's License agreement if users can charge for providing third parties with the raw subject data, which has been extended or improved with other value-added services or information.

Beijing's Disclaimer goes further: providing that the applications developed by users are subject to government approval, following that the government has the power to delete or block the applications. ${ }^{151}$ This restriction, which is seldom seen in other jurisdictions, reflects the

146 See Chris Corbin 'PSI Policy Principles: European Best Practice'in Brian Fitzgerald (ed) Access to public sector information: Law, technology \& policy (Sydney University Press, Sydney, 2010) vol 2161 at 167.

147 EU Amending Directive, above n 32, at 3.

148 But see Chui, Farrell and Van Kuiken, above n 19, at 164 (claiming unrestrictive rights to use government data).

149 BJ Data, above n 109.

150 Open Data of Qingdao Government, above n 107.

151 BJ Data, above n 109. 
political reality of the region, which tends towards government control of information and market activities. All these restrictions may discourage new business models and value-added service built upon OGD.

In summary, a government's choice of open licensing terms is quite different from that of the private sector. Businesses or communities usually link the choice over terms to contributors' incentives to contribute, costs to provide this incentive and the sustainability of the commons' projects. ${ }^{152}$ However, such considerations may not exist in the context of government data that is continuously generated as an outcome of governmental functions. In other words, a government's selection of open data licences tends to reflect its policy goals, which are typically not the same as those addressed in private business or commons settings.

\subsection{Licence Compatibility}

Compared to the OGD terms released in other jurisdictions in the Greater China Region, Taiwan's Open Government Data License is uniquely devised with a compatibility provision. This provision serves to facilitate the compatibility between different versions of the licence and between the licence and Creative Commons Attribution License 4.0 International. ${ }^{153}$ From a comparative perspective, such compatibility provisions are quite common in OGD licences outside of the Greater China Region. ${ }^{154}$ Compatibility, or interoperability, between licences means users can legally combine works that are subject to different public licences. ${ }^{155}$ Licence compatibility is especially important in scientific fields, such as environmental protection and climate change, where users have an urgent need to use data from sources with different licences. ${ }^{156}$ Because

152 See Clark D Asay 'A Case for the Public Domain' (2013) 74 Ohio St LJ 753 at 773-780; Jyh-An Lee 'Organizing the Unorganized: The Role of Nonprofit Organizations in the Commons Communities' (2010) 50 Jurimetrics J 275 at 313 (noting that commons communities can sustain by using licensing terms to coordinate individual contributors).

153 NDC, above n 132.

154 See, for example, 'Open Database License (ODbL) v1.0' Open Data Commons opendatacommons.org at 4.4(e); Mewhort, above n 89, at 3 and 20-21 (noting that the British Open Government Licence was intentionally crafted to be compatible with CC licenses).

155 See Christopher S Brown 'Copyleft, The Disguised Copyright: Why Legislative Copyright Reform Is Superior to Copyleft Licenses' (2010) 78 UMKC L Rev 748 at 772-774; Jyh-An Lee 'The Greenpeace of Cultural Environmentalism' (2010) 16 Widener L Rev 1 at 32-33; Martynas Mockus and Monica Palmirani 'Open Government Data Licensing Framework' in Andrea Kö and Enrico Francesconi (eds) Electronic Government and the Information Systems Perspective (Springer, 2015) 287 at 290-292; Morando, above n 85, at 445-448.

156 See Estelle Derclaye 'The Role of Copyright in the Protection of Environment and the Fight Against Climate Change: Is the Current Copyright System Adequate?' (2014) 5(2) WIPO J 152 at 158. 
public licences and declarations aim to facilitate greater distribution and reuse of the subject materials, such public licences inevitably include a compatibility provision so that users can legally combine content licensed under different licences. ${ }^{157}$

\subsection{Government Data in the Public Domain}

Some scholars and policymakers assert that, from a policy perspective, the works created by state employees should be in the public domain and not protected by IP at all. ${ }^{158}$ For example, the Dutch Council of State opined in 2009 that the City of Amsterdam could not legally impose any restriction on a company's use of the City's database because it was built with tax money. ${ }^{159}$ In other words, the City's government did not own the database. In countries like the United States, there are statutory public domain rules that prohibit the federal government from copyrighting works it produces; however, governments may still own copyrights assigned by others. ${ }^{160}$

Even if a government can own copyright, the originality standard may prevent it from claiming copyright over a government database. ${ }^{161}$ Originality is the standard for copyright protection internationally, ${ }^{162}$ and in the Greater China region as well. ${ }^{163}$ Courts in Mainland China

157 See 'Open Government Licence for Public Sector Information' National Archives www.national archives.gov.uk.

158 Okediji, above n 86, at 338-339; Gurin, above n 5, at 9 ('governments should make the data they collect available to taxpayers who've paid to collect it'); Marcowitz-Bitton, above n 3, at 415 (introducing the argument that government works 'should be accessible to all, uninhibited' by the argument that taxpayers shall have free access to government-generated data).

159 Janssen, above n 2, at 451.

16017 USC $\$ 105$ ('[c] opyright ... is not available for any work of the United States Government'); see also Marcowitz-Bitton, above n 3, at 420 (explaining that ' $[\mathrm{t}$ ] he reason behind 17 U.S.C. $\$ 105$ is to ensure that government information remains in the public domain in order to best serve the public interest'); Okediji, above n 86, 343-345 (explaining the evolution of public domain rule on government works in the United States).

161 See Beth Ford 'Open Wide the Gates of Legal Access' (2014) 93 Or L Rev 539 at 546.

162 See Sterling, above n 90.

163 In Mainland China, art 14 of Copyright Law of the PRC 1990 (China) states that: 'A collection of preexisting works or passages therefrom, or of data or other material which does not constitute a work, if manifesting the originality of a work by reason of the selection or arrangement of its contents, is a compilation. The copyright in such compilation shall be enjoyed by the compiler, provided that the exercise of such copyright does not prejudice the copyright in the preexisting works'. Article 2 of Implementing Rules for Copyright Law 1991 (China) stipulates: "The term "works" as referred to in the Copyright Law means intellectual creations with originality in the literary, artistic or scientific domain, insofar as they can be reproduced in a tangible form.' Originality requirement can be found in Copyright Ordinance 1997 (Hong Kong), s 2(1)(a): 'original literary, dramatic, musical or artistic work.' Article 7.1 of Copyright Act 2016 (Taiwan) states that: 'A compilation work is a work formed by the creative selection and arrangement of materials, and shall be protected as an independent work.' 
and Taiwan have ruled that originality requires independent creation and a minimum degree of creativity. ${ }^{164}$ In Hong Kong, originality requires authors to show the exercise of skill and judgment. ${ }^{165}$ Consequently, facts, or information automatically generated by a machine or algorithm, cannot be protected by copyright because they lack originality. ${ }^{166}$ Database creators gain copyright protection of compilations and databases only if the selection, coordination or arrangement of the contents is sufficiently original. ${ }^{167}$ However, this is not the case for some government databases, which include statistics, census data, fiscal data, budget information, parliamentary records, election records, property registration, facts about school locations and performance, other factual information, or that are created automatically and mechanically by machine. ${ }^{168}$ In other words, government databases often lack originality and therefore cannot be protected by copyright. ${ }^{169}$ This may explain why government agencies in Mainland China do not typically provide a licence agreement or terms for the use of copyright works. If the database is not copyrightable, from a copyright perspective there is no need to design such a licence or appropriate terms. Instead, the courts will likely treat any terms of use relating to access and use of such a database as contractual. ${ }^{170}$

164 See Jyh-An Lee 'Copyright Protection of Database in Taiwan' (2011) 188 Taiwan L Rev 36 at 39; Taiwan Intellectual Property Office (TIPO), Interpretation No. 980427a, April 27, 2009; Changchun Publishing Group v Ji Lin University Publishing \& United Book City Jilin HC Ji Min San Zhi ZhongZi 68(2015).

165 Kenneth Wong and Alice Lee Intellectual Property Law and Practice in Hong Kong (Sweet \& Maxwell, Hong Kong, 2014).

166 See Frederick Abbott, Thomas Cottier and Francis Gurry International Intellectual Property in an Integrated World Economy (3rd ed, Wolters Kluwer, 2015) at 535; Scassa, above n 5, at 1782-1783 and 1787-1788.

167 See Feist Publications Inc v Rural Telephone Services Company 499 US 340 (1991) at 345.

168 See Marcowitz-Bitton, above n 3, at 413 (stating that government data includes 'national statistics, budget information, parliamentary records, data about the location of schools and their performance, information about crimes, election records, financial data, and more') and 415; Okediji, above n 86, at 334; Tauberer, above n 2, at 115 ('government data normally represents facts about the real world (who voted on what, environmental conditions, financial holdings)'); Borgesius, Gray and van Eechoud, above n 18, at 2094 (noting that government data includes statistics, land registries, business registers, or earth observation data); Lee, above n 5, at 54-56 (noting that common highvalue datasets are those of company register, insolvency and bankruptcy record, government contract, various statistics, and so on); Ubaldi, above n 2, at 6 and 23 (noting that government data consists of business information, registers, geographic information, meteorological information, social data on statistics and transport information).

169 See Marcowitz-Bitton, above n 3, at 415; Scassa, above n 5, at 1785; Paul Miller, Rob Styles and Tom Heath 'Open Data Commons, A License for Open Data' (22 April 2008) CEUR Workshop Proceedings ceur-ws.org (similarly holding that data, datasets and databases are mostly not copyrightable creative works); Scassa, above n 5, at 1776 (stating that it is difficult to identify authorship in government data).

170 Jacobsen $v$ Katzer, above n 138. Note: this was a decision of the United States Supreme Court. 
In sum, government databases are not protected by copyright unless they meet the originality standard in copyright law. Although some government databases may attain the relevant threshold of original expression in their jurisdiction and, thus, qualify for copyright protection, most government databases do not, such as mundane collections of statistics, factual information or information automatically produced by machine or algorithm. Governments in EU countries can obtain sui generis protection for their databases if they made a substantial investment into the creation of the databases. ${ }^{171}$ However, this sui generis right is not available in the Greater China jurisdictions.

Typically, copyright or neighbouring rights protect works subject to open licences, such as Creative Commons licences. Similarly, most open data licences are designed based on the presumption that the subject government's data or database is protected by copyright. ${ }^{172}$ For example, Hong Kong's Terms and Conditions require users to recognise the government's ownership of IP in the data. ${ }^{173}$ Taiwan's Open Government Data License identifies itself as a copyright licence. ${ }^{174}$ Beijing's Disclaimer provides that the government owns property rights over the content. ${ }^{175}$ Article 1 of Zhejiang's Statement of the Website is the 'declaration of copyright' of all content on the website. ${ }^{176}$

The use of copyright-dependent terms and statements logically imply that the relevant terms of use do not apply to databases that are not protected by copyright. Nonetheless, a significant number of databases in those OGD portals are automatically and mechanically created, and, therefore, not copyrightable. Consequently, the legal (or, more specifically, copyrightdependent) arrangements around the access and use of databases may not be consistent with the legal status of the databases.

171 Directive 96/9/EC on the Legal Protection of Databases [1996] OJ L77/20 at 20.

172 Scassa, above n 5, at 1804; Tauberer, above n 2, at 107 (' $[\mathrm{w}]$ hen a work is copyrighted, a license is required to undo or partially undo the all-rights-reserved default rule') and at 144 ('[o]pen licensing ... is subject to copyright protections'); Bannister, above n 61, at 1099 ('Creative Commons licensing movement aims to provide a standardised infrastructure for the open licensing of copyright protected material').

173 See Terms and Conditions of Use, above $\mathrm{n} 96$.

174 NDC, above n 132.

175 BJ Data, above n 109.

176 Zhejiang Provincial Government Portal, above n 110, at 1. 
I now consider the situation in regard to governments that apply public licences to databases that are not protected by copyright or database rights. What is the legal effect of such licences? It is possible that governments do not conduct due diligence regarding the legal status of the subject data and databases. Based on the author's personal experiences of providing OGD consultation to the public sectors in the Greater China region, this is most likely because of government mentality regarding control over data and databases. Government officials may hesitate to recognise the public domain nature of the sorts of databases over which they are accustomed to exerting their full control. They may not understand that although the government is in charge of database governance, the government cannot legally claim database ownership (in terms of copyright). Nevertheless, they may claim ownership of the physical copy of the database or control access and use through their possession of the database.

From a legal perspective, it is worth exploring the effects of these licences and terms of use if the underlying database is in the public domain. There are two possible approaches to this question, both of which are based on an implication of the Jacobsen $v$ Katzer ruling suggesting that contract law applies to public licences. ${ }^{177}$ The first interpretation is that the contract may be void, or partly void, as an illegal contract, given that the subject matter database in the contract is not owned by the licensor and is in the public domain. The database should thus be free to everyone. ${ }^{178}$ If the underlying database is not protected under applicable law, a licence is unnecessary. ${ }^{179}$ Indeed, asserting copyright over public domain materials may at worst be defined as 'copyfraud': an activity that may stifle creativity and free speech. ${ }^{180}$

The second possible solution is to recognise the validity of the agreement and treat it as a binding contract between the database holder and the user. Expressed differently, even if there are no underlying IP rights to support a copyright licence, ${ }^{181}$ the agreement itself is still a contract that can legally

177 Jacobsen $v$ Katzer, above n 138.

178 See Marcowitz-Bitton, above n 3, at 438.

179 'Comments on the Open Database License Proposed by Open Data Commons' Creative Commons sciencecommons.org.

180 Jason Mazzone 'Copyfraud' (2006) 81 NYU L Rev 1026 (2006) at 1028-1030.

181 But see Christopher M Newman 'A License Is Not a "Contract Not to Sue": Disentangling Property and Contract in the Law of Copyright Licenses' (2013) Iowa L Rev 1101 at 1114 (noting that a licence needs to be granted by the titleholder of the property). 
oblige database users to fulfil attribution or other duties. ${ }^{182}$ This contract theory has, however, been criticised as imposing unnecessary restrictions on public domain resources. ${ }^{183}$

Even if the open licence agreement is valid and enforceable between the licensor and licensee, whether the database is protected by copyright makes an important difference when the licensor attempts to enforce their legal right against a third party. Given the transparent nature of OGD policy, it is quite possible that third parties have not obtained the database directly from the government, but from elsewhere. These third parties may argue that they are not parties to public licences or term of use and thus are not bound by the licence agreement. While contractual or licensing rights and obligations are in personam and, thus, restricted to the specific parties to the contract or licence, property rights are in rem and good against third parties. The risk of third party use of government data in the public licence sphere is higher than that of third party use in a proprietary licensing scenario, as, with the latter, the number of licensees is limited and the licensor may adopt various contractual or technical measures to control the flow of licensed materials. By contrast, those adopting public licences usually have much less understanding and control regarding the flow of licensed materials. Traditionally, even though copyright owners cannot sue the third parties for breach of the licence agreement, they can still claim copyright infringement against them. ${ }^{184}$ Nevertheless, if the subject database is in the public domain, the database originators will not have any grounds to sue the third party who does not comply with the licence agreement. Instead, the originator might be able to sue the licensee.

\subsection{Attribution}

Almost all OGD licences or terms in the Greater China region contain an attribution requirement. This practice would involve a fundamental inquiry into the relationship between copyright and attribution. Normally, a right of attribution is a moral right. ${ }^{185}$ Authors may not retain ownership of their copyright but they can require users or licensees to attribute credit to them. By claiming the original copyright ownership over databases,

182 Creative Commons, above n 179.

183 Jyh-An Lee 'Licensing Open Government Data' (2017) 13 Hastings Bus LJ 207 at 234.

184 See also Brown, above n 155, at 767 ('if the user [of a CC license] cannot rely on the license then they will have no way to know whether their use constitutes copyright infringement').

185 Berne Convention for the Protection of Literary and Artistic Works 1161 UNTS 31 (opened for signature 9 September 1886, entered into force 5 December 1887), art 6bis. 
governments justify using public licences to entail users giving credit on the basis of moral rights, although, technically, a government cannot be an author and, thus, cannot have moral rights. Governments may be owners of copyright, but only individuals can be authors with moral rights. Therefore, in this context, attribution is a contractual requirement.

Since OGD policies normally promote access to, and reuse of, data for free or at nominal costs, ${ }^{186}$ every restriction in the licensing terms that increases users' costs needs to be justified. Therefore, it is worth exploring why attribution is necessary in open data licences. Some researchers argue that the attribution requirement is a government's instrument to control speech because every restriction on the use of data is a form of censorship. ${ }^{187}$ This argument is flawed in at least three ways: first, free speech as a constitutional right is still subject to some limitations; ${ }^{188}$ second, there is no empirical evidence or theoretical support indicating that the attribution requirement in OGD licences generates a chilling effect or any barriers to freedom of speech; and third, it is not articulated why governments would intend to restrict speech via the attribution requirement. We can hardly imagine how a government would be able to use the attribution requirement to silence others from voicing opinions with which it disagrees.

Some other scholars have suggested that attribution can guarantee the accuracy and reliability of the data provided by governments. ${ }^{189}$ However, such an argument may not be validated if we read through government data licences. It is quite costly to maintain the accuracy and precision of data. ${ }^{190}$ Poor quality has been a problem for government data; ${ }^{191}$ consequently, making it openly available highlights its incompleteness and inaccuracy. Most open data licences include a liability disclaimer refusing to take responsibility for the data's accuracy, correctness or completeness. The data or database is licensed by the licensor 'as is' and without any warranty of data quality. The disclaimer provision in traditional public

186 See above n 32.

187 Tauberer, above n 2, at 109.

188 See David S Bogen 'The Origins of Freedom of Speech and Press' (1983) 42 Md L Rev 429 at 431 and 436-437; Irene M Ten Cate 'Speech, Truth, and Freedom: An Examination of John Stuart Mill's and Justice Oliver Wendell Holmes's Free Speech Defenses' (2010) 22 Yale JL \& Human 35 at 69; Ronald J Krotoszynski 'A Comparative Perspective on the First Amendment: Free Speech, Militant Democracy, and the Primacy of Dignity as a Preferred Constitutional Value in Germany' (2004) 78 Tul L Rev 1549 at 1551 and 1554-1559.

189 See Marcowitz-Bitton, above n 3, at 414-415.

190 Tauberer, above n 2, at 118 .

191 See Gurin, above n 5, at 233; Tauberer, above n 2, at 149. 
licence agreements is typically subject to IP infringement claimed by third parties, ${ }^{192}$ but, in open data agreements, the disclaimer provision also excludes any legal liability associated with data error. ${ }^{193}$ If the attribution terms in open data licences are intended to ensure data quality, then the disclaimer provisions become unnecessary in the licence agreement.

The right to be identified, or right of attribution or paternity, is the most important category of moral rights. ${ }^{194}$ Leaving aside the fact that governments cannot have moral rights, it is worth examining a government's attitude toward appropriate attribution from the perspective of moral rights theory. It should be noted that a government's generation of data differs from that of individuals or enterprises making creative works. Most government data and databases are produced as a by-product of a government's daily functions. ${ }^{195}$ Therefore, although correct attribution can provide non-pecuniary rewards or incentives to authors of creative works, ${ }^{196}$ the same cannot be justified in the context of government data. In addition, attribution rights have traditionally represented an artist's personal connection to his or her creative works. ${ }^{197}$ This personal link hardly exists in the generation of government database. More importantly, as noted above, moral rights are personal rights, which pertain only to authors. Businesses, governments and other organisations, therefore, cannot claim moral rights.

192 See Stephen McJohn 'The GPL Meets the UCC: Does Free Software Come with a Warranty of No Infringement?' (2014) $15 \mathrm{~J}$ High Tech L 1 at 19.

193 For example, all CC licences come with this disclaimer: 'Unless otherwise separately undertaken by the Licensor, to the extent possible, the Licensor offers the Licensed Material as-is and asavailable, and makes no representations or warranties of any kind concerning the Licensed Material, whether express, implied, statutory, or other. This includes, without limitation, warranties of title, merchantability, fitness for a particular purpose, non-infringement, absence of latent or other defects, accuracy, or the presence or absence of errors, whether or not known or discoverable.'

194 See Paul Goldstein and Bernt Hugenholtz International Copyright: Principles, Law and Practice (3rd ed, Oxford University Press, 2013) at 361; Mira T Sundara Rajan 'Creative Commons: America's Moral Rights?' (2011) 21 Fordham Intell Prop Media \& Ent LJ 905 at 926.

195 See above $\mathrm{n} 3$.

196 See Jane C Ginsburg 'Moral Rights in a Common Law System' (1990) 1(4) Ent L Rev 121 at 122; Catherine L Fisk 'Credit Where It's Due: The Law and Norms of Attribution' (2006) 95 Geo LJ 49 at 56-60; Asay, above n 152, at 792 (noting that attribution is a significant drive for contributions in free or open source software or open content communities).

197 See Elizabeth M Bock 'Note: Using Public Disclosure as the Vesting Point for Moral Rights under the Visual Artists Rights Act' (2011) 110 Mich L Rev 153 at 161-162; Robert C Bird 'Moral Rights: Diagnosis and Rehabilitation' (2009) 46 AM Bus LJ 407 at 426 ('Le droit moral [moral right] ... addresses legal rights that acknowledge a personal legal connection between an author and her creations'); Adolf Dietz 'Moral Rights and the Civil Law Countries' (1995) 19 Colum VLA JL \& Arts 199 at 207 (noting that moral rights in the Germany Copyright Act focus on the authors' personal relationship with his or her creative works). 
Nonetheless, governments occasionally gain political advantages from the attribution requirement because it helps to craft a public impression that they have released some valuable data to society. In this sense, governments, just like authors of creative works, benefit from situations where the relationship between the makers and their works is visible. ${ }^{198}$ Greg Lastowka correctly indicated that attribution helps creators gain advantages in the reputation market. ${ }^{199}$ The same reasoning can be applied to governments' open data licences in which the attribution requirement may help them earn a positive public reputation.

Another argument in favour of attribution is the 'public interest theory', which states that the public can benefit from the disclosure of attribution. ${ }^{200}$ This theory is more suited to OGD policy. As the primary goal of OGD is to promote transparency, accountability and economic development, the public has a stake in knowing whether the data is provided by the government and which government agency provided which data, dataset or database. The disclosure of this information can better enable citizens to assess the performance of government agencies and whether, and to what extent, the data release can help economic development.

\section{Conclusion}

Open data may contribute to the achievement of a wide range of social, economic and political goals. Nevertheless, it also involves a variety of legal issues. The choice (or design) of a licence, or the terms of use for OGD is not only a legal issue but also a policy issue. Based on an analysis of the legal environment for OGD in the Greater China region, this study argues that a government's decisions regarding open data licences reveal the priorities of its policy goals, which may be associated with transparency,

\footnotetext{
198 See Silke Von Lewinski International Copyright Law and Policy (Oxford University Press, Oxford, 2008) at 51.

199 Greg Lastowka 'Digital Attribution: Copyright and the Right to Credit' (2007) 87 BU L Rev 41 at 60-61; Bock, above n 197, at 168 ('integrity and attribution are concerned with the reputation of the artist').

200 See Ginsburg, above n 196, at 122; Fisk, above n 196, at 54 ('[a]ttribution is a type of signal, and it operates in labor and other markets plagued by information asymmetries in which reliable signals are important'); Henry Hansmann and Marina Santilli 'Authors' and Artists' Moral Rights: A Comparative Legal and Economic Analysis' (1997) 26 J Legal Stud 95 at 107 (noting that public interests are enhanced by attribution rights, which prevent the public from being misled about the work); Margaret Ann Wilkinson 'The Public Interest in Moral Rights Protection' (2006) Mich St L Rev 193 at 212-216 (analysing moral rights' public-interests function in information provision).
} 
accountability, collaboration, economic growth or political control. If the primary policy goal is to promote innovation and economic development, the terms or licences of OGD should be the least restrictive. Based on this line of reasoning, the provision in Beijing's Disclaimer regarding government's control of applications developed by users implies that control of information is a higher priority than innovation and economic development on the government's agenda.

As a significant number of government databases in the Greater China region do not meet the originality requirement and thus are not copyrightable, these licences may not prove effective in many OGD scenarios. In Greater China jurisdictions, where there is no sui generis database right, these licences may not be legally effective for noncopyrightable data and databases.

Moreover, attribution is the most common, and occasionally the only, requirement in OGD licences. The existence of this design in open data licences cannot be explained by traditional copyright theories because the data can hardly present a government's personality and governments do not need user attribution as an incentive to generate data. Nonetheless, these provisions can be understood by applying the public interest theory of moral right, suggesting that the public can benefit from the disclosure of attribution. As the primary goal of OGD is to promote transparency, accountability and economic development, the public has a vested interest in knowing whether the government provides the data and which government agency has produced it.

Through a study of OGD licences in the Greater China region, this chapter not only illustrates different phases of OGD development but also analyses potential and unsettled copyright issues therein, such as moral rights and the legality of licences associated with uncopyrightable materials. The dynamic OGD experiences from three main jurisdictions in the Greater China region, namely mainland China, Hong Kong and Taiwan, are, therefore, valuable for others that aim to implement OGD policies for various policy goals. 
This text is taken from Making Copyright Work for the Asian Pacific: Juxtaposing Harmonisation with Flexibility, edited by Susan Corbett and Jessica C Lai, published 2018 by ANU Press, The Australian National University, Canberra, Australia.

doi.org/10.22459/MCWAP.10.2018.07 